EJP 00724

\title{
Effect of methadone on plasma arginine vasopressin level and urine production in conscious dogs
}

\author{
Ludo J. Hellebrekers ${ }^{1, *}$, Jan A. Mol ${ }^{1}$, Walter E. Van den Brom ${ }^{1}$ \\ and Tjeerd B. Van Wimersma Greidanus ${ }^{2}$ \\ ' Small Animal Clinic and Subdepartment of Veterinary Anesthesiology (L.J.H.), Faculty of Veterinary Medicine, University of Utrecht, \\ Yalelaan 8, 3508 TD Utrecht, and ${ }^{2}$ Rudolf Magnus Institute for Pharmacology, Medical Faculty, University of Utrecht, \\ Vondellaan 6, 3521 GD Utrecht, The Netherlands
}

Received 14 August 1986, revised MS received 8 December 1986, accepted 3 February 1987

The aim of this study was to examine the effect of i.v. methadone on the plasma arginine-vasopressin (AVP) levels and urine production in 9 conscious dogs. A highly significant increase from the baseline plasma AVP values of below $3 \mathrm{pg} / \mathrm{ml}$ occurred within $5 \mathrm{~min}$ following methadone administration. Maximum levels were reached within 30-50 min post-injection and varied from 18.5 to $100 \mathrm{pg} / \mathrm{ml}$. A significant decrease in urine production was not seen under these experimental conditions. Mean arterial blood pressure did not change significantly during the experiment. Apart from the partial influence of the methadone-induced respiratory acidosis, we postulate a direct relationship between i.v. administration of methadone and the increased plasma AVP levels in dogs.

Methadone; Arginine-vasopressin; (Dog)

\section{Introduction}

The purpose of this study was to examine the possible effect of i.v. opiate administration on plasma arginine-vasopressin (AVP) level and urine production in the dog. To this date, only sparse and conflicting information about opiate-induced changes in AVP release in the dog has been presented since De Bodo's report in 1944 (De Bodo, 1944). Furthermore, due to variations in experimental species, states of hydration or mental awareness (conscious vs. anesthetized) and experimental protocol, extrapolation from a study on one species to one on another species is hazardous.

\footnotetext{
* To whom all correspondence should be addressed: Subdepartment of Veterinary Anesthesia, Postbox 80.153, Yalelaan 12, 3508 TD Utrecht, The Netherlands.
}

Montastruc et al. (1980) found a morphine-induced, naloxone-sensitive, antidiuresis in normal dogs but not in dogs with diabetes insipidus. However, experiments performed by HuidobroToro (1980) showed that the antidiuretic response following morphine administration was similar in Brattleboro and in normal rats. This would imply that AVP does not play a major role in the morphine-induced antidiuresis. Rockhold et al. (1983) reported a rise in plasma AVP after morphine administration in dogs. These authors postulated a causative relationship between the decreased blood pressure after opiate administration and the concurrent rise in plasma AVP levels.

We recorded plasma AVP levels and urine production in conscious euhydrated dogs after i.v. administration of methadone, like morphine, a $\mu$-type opiate agonist (Iwamoto and Martin, 1981) frequently used in canine anesthesia. 


\section{Materials and methods}

\subsection{Experimental animals}

Nine adult mixed breed dogs $(8$ males and 1 female) were used for the experiment. Body weight varied between 14.3 and $38.0 \mathrm{~kg}$ with a median value of $26.5 \mathrm{~kg}$. Food, but not water, was withheld for $18 \mathrm{~h}$ before the start of the experiment.

\subsection{Experimental protocol}

The dogs were trained to lie on their side during the experiment. Percutaneous placement of cephalic vein (Braunule, 18 gauge, B. Braun, Melsungen, West-Germany) and femoral artery (Secalon, 16 gauge, British Viggo, Swindon, Great Britain) catheters was performed. Insertion of the femoral catheter was facilitated by s.c. infiltration with $5 \mathrm{ml}$ of a lidocaine $\mathrm{HCl}$ solution. The bladder was catheterised (Portex Ltd., Hythe, Kent, Great Britain) and emptied less than 2 min before the start of the experiment. Methadone (methadoni $\mathrm{HCl}, 10 \mathrm{mg} / \mathrm{ml}$, Gist-Brocades, Delft, the Netherlands), in a dose of $1 \mathrm{mg} / \mathrm{kg}$ body weight, was injected into the cephalic vein. Blood samples were drawn in heparinized syringes via the arterial line at $-1,5,10,15,20,30$ and $60 \mathrm{~min}$. At this time $(60 \mathrm{~min})$ methadone was injected and the sampling sequence was repeated $(65,70,75,80$, $90,120 \mathrm{~min}$ ) and extended by 2 additional samples at 150 and $180 \mathrm{~min}$.

\subsection{AVP extraction and radioimmunoassay}

Plasma was frozen immediately after centrifugation and was stored at $-80^{\circ} \mathrm{C}$ for serial assaying of AVP.

AVP extraction was based on a method using small columns packed with octadecasilyl silica (C18 Sep-Paks, Waters Assoc., Milford, MA, USA) as described previously (La Rochelle et al., 1980; Glanzer et al., 1984; Galard et al., 1985). Extraction recovery was determined by the addition of various concentrations of AVP to a plasma pool from a dog which had received a water load. The extraction efficiency amounted to $82 \pm 3 \%$ (mean \pm S.D.).
The antiserum, 'WIE', raised against synthetic AVP showed the following cross-reactivities at $50 \%$ displacement of ${ }^{125}$ I-AVP, AVP-(4-9): 100\%; vasotocin: $100 \%$; lysine-8-vasopressin: $10 \%$ and oxytocin: $<0.01 \%$, respectively. The intra-assay coefficient of variation averaged $5.9 \%$. Synthetic AVP (Sigma, St. Louis, MO, USA) was used for preparing standards ranging from 0.25 to 250 $\mathrm{pg} / \mathrm{ml}$, in RIA buffer consisting of $0.1 \mathrm{M}$ phosphate buffer (pH 7.5), $1 \mathrm{mM}$ EDTA and 0.1\% (w/v) HSA (Serva, Heidelberg, West-Germany). The RIA tubes, containing $0.2 \mathrm{ml}$ standard or plasma extract and $0.1 \mathrm{ml}$ antiserum $(1: 200000$ in assay buffer) were incubated for $20 \mathrm{~h}$ at $4^{\circ} \mathrm{C}$. Subsequently, $100 \mu \mathrm{l}$ of (3-125 I-iodotyrosyl)-AVP (6250 d.p.m.; specific activity $2100 \mathrm{Ci} / \mathrm{mmol}$, Amersham International, Great Britain) was added and incubated for another $20 \mathrm{~h}$. For separation of bound and free tracer, $0.1 \mathrm{ml}$ second antibody-coated cellulose (Saccel, Wellcome Laboratories) was added, mixed thoroughly and incubated for $30 \mathrm{~min}$. After addition of $1 \mathrm{ml}$ distilled water $\left(4^{\circ} \mathrm{C}\right)$, the tubes were centrifuged at $3000 \times \mathrm{g}$ for $15 \mathrm{~min}$ at $4^{\circ} \mathrm{C}$. The supernatants were aspirated, and bound ${ }^{125}$ I-AVP was estimated in a gamma counter. The detection limit of the assay was determined at $0.5 \mathrm{pg} / \mathrm{ml}$ AVP. The results were calculated from a linear regression curve obtained by logit-log transformation of the standard curve (Rodbard and Lawald, 1970).

\subsection{Urine production and osmolality determination}

Urine production was measured by a dilution method. For that purpose, a $20 \mathrm{ml}$ volume of distilled water was instilled in the bladder which had been emptied at the beginning of the experiment. The water was labeled by means of $1 \mathrm{mCi}$ of ${ }^{99 \mathrm{~m}}$ Tc-DTPA (diethylene triamine penta acetic acid). During refilling, the water was thoroughly mixed with the remainder of the bladder content by repeated removal and administration. Uptake of the radioactive isotope by the bladder wall was checked by repeated blood sampling; no specific radioactivity was detectable in these samples. A $1.04 \mathrm{ml}$ sample was withdrawn at $15 \mathrm{~min}$ intervals from the bladder and its specific radioactivity was measured in a gamma counter (Gamma 4000, 
Beckman, Fullerton, CA, USA).

The volume of the bladder content could be determined by comparison of the specific activity of the samples with a standard which was a known fraction of the amount of activity administered. The bladder content that remained after emptying was determined from a sample taken immediately after the start of the experiment. Taking this value and the predrawn volumes into account, the accumulated volume of the urine produced was then calculated as a function of time. The time derivative of this volume curve yields the urine production rate as a function of time.

A constant production rate would imply a linear increase in the accumulated volume with respect to time. Since this may not be assumed a priori, a polynomial regression of the third degree was applied to the accumulated volume data instead of a linear regression. The production rate was calculated as the time derivative of this polynomial.

The osmolality of the samples was measured by a vapor pressure method (Wescor Inc., Logon, Utah, USA). The osmolality of the urine produced was calculated as a function of time from these values and the results of the volume measurements.

\subsection{Biochemical monitoring}

All blood samples were processed immediately for blood gas and acid-base analysis (Acid Base Analyzer, Instrumentation Laboratory Type 1302, Allied, London, Great Britain) and Packed Cell Volume (PCV, microhematocrit method). After centrifugation at $1000 \times g$, serial determinations of plasma sodium, potassium and chloride concentrations were performed using flame photometry (Klinaflame, Beckman, Fullerton, CA, USA) and colorimetry (Chlorocounter, Marius, Utrecht, the Netherlands), respectively. Plasma osmolality was measured with a vapor pressure method (Wescor Inc., Logon, UT, USA).

\subsection{Hemodynamic monitoring}

Pulsatile and mean arterial pressure were recorded on a Gould Brush 440 recorder (Gould,
Oxnard, CA, USA) by means of a Statham P23 ID (Gould, Oxnard, CA, USA) strain gauge transducer and a HP $78205 \mathrm{C}$ amplifier (Hewlett Packard, Waltham, MA, USA). Heart rate was recorded from an ECG tracing, lead II.

\subsection{Statistical analysis}

The results were analyzed using the two-way analysis of variance and the Student-NewmanKeuls multiple comparison test. Differences were considered to be significant at the $\mathrm{P}<0.05$ level.
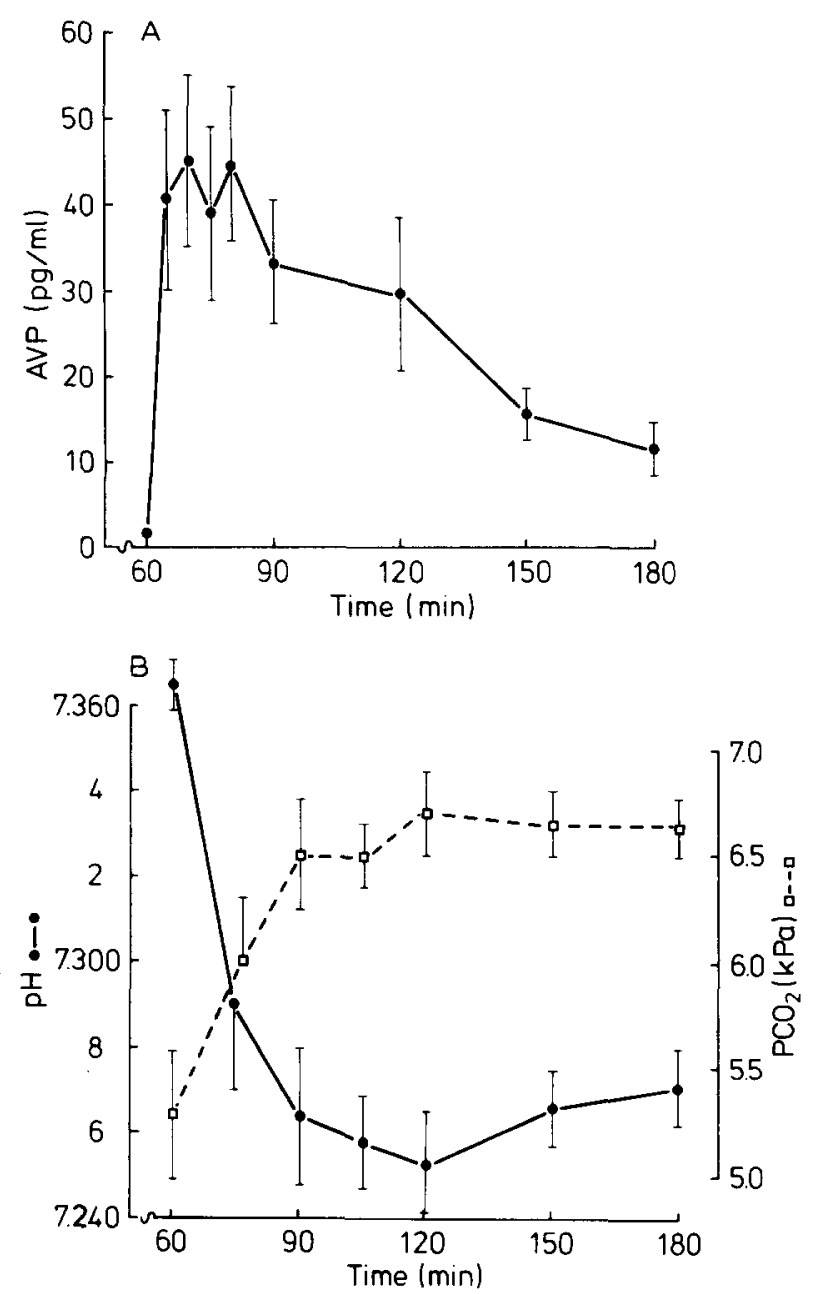

Fig. 1. (A) Effect of i.v. methadone administration (time 60) on plasma AVP levels. Data presented as means \pm S.E.M. (B) Effect of i.v. methadone administration (time 60) on arterial $\mathrm{pH}$ and $\mathrm{pCO}_{2}$ levels. Data presented as means \pm S.E.M. 


\section{Results}

\subsection{Plasma AVP levels}

In samples collected before methadone administration, plasma AVP levels varied from 0.9 to $2.5 \mathrm{pg} / \mathrm{ml}$ with an average of $1.7 \pm 0.2 \mathrm{pg} / \mathrm{ml}$. Within 5 min after methadone administration, the plasma AVP levels increased to or above $10 \mathrm{pg} / \mathrm{ml}$ AVP level (fig. 1A). Maximum levels were reached within 30-50 min post-injection and varied from 18.5 to $100 \mathrm{pg} / \mathrm{ml}$. The mean maximum increase to $45.1 \pm 10.4 \mathrm{pg} / \mathrm{ml}$ was reached $10 \mathrm{~min}$ post-injection. In 5 of the 9 dogs, the plasma AVP levels had not returned to below $5 \mathrm{pg} / \mathrm{ml} 2 \mathrm{~h}$ after injection of methadone. All values obtained after methadone administration were calculated to be significantly different from the baseline values.

\subsection{Urine production and osmolality}

The polynomial regression of the urine volume on time showed that the urine production rate increased slightly but significantly from a baseline value of $6.52 \pm 1.35 \mathrm{ml} / 10 \mathrm{~kg}$ body weight $/ \mathrm{h}$ (table 1). The urine osmolality data presented (table 1) are the osmolalities of the urine produced in the particular time interval. There were no significant differences from the baseline value of $1440 \pm 87 \mathrm{mOsm} / 1$.

\section{TABLE 1}

Values for urine production and osmolality before and after methadone administration at $\mathrm{t}=60$. Urine production, corrected for duration of time interval, is expressed as $\mathrm{ml} / 10 \mathrm{~kg}$ body weight $/ h$. Data presented as means \pm S.E.M.

\begin{tabular}{lll}
\hline $\begin{array}{l}\text { Time interval } \\
(\mathrm{min})\end{array}$ & $\begin{array}{l}\text { Urine production } \\
(\mathrm{ml} / 10 \mathrm{~kg} \text { body } \\
\text { weight } \text { per } \mathrm{h})\end{array}$ & $\begin{array}{l}\text { Osmolality } \\
(\mathrm{mOsm} / \mathrm{l})\end{array}$ \\
\hline $0-60$ & $6.52 \pm 1.35$ & $1440 \pm 87$ \\
$60-75$ & $7.24 \pm 1.32$ & $1311 \pm 178$ \\
$75-90$ & $7.56 \pm 1.36$ & $1454 \pm 164$ \\
$90-105$ & $7.92 \pm 1.40$ & $1387 \pm 111$ \\
$105-120$ & $8.24 \pm 1.44$ & $1897 \pm 307$ \\
$120-150$ & $8.84 \pm 1.66$ & $1462 \pm 163$ \\
$150-180$ & $9.62 \pm 2.30$ & $1401 \pm 120$ \\
\hline
\end{tabular}

\subsection{Biochemical monitoring}

The basal PCV values for individual animals varied from 38 to $57 \%$ with an average of $44.8 \pm$ $1.0 \%$. The PCV was significantly elevated following methadone administration. The group average rose to $48.1 \pm 0.7 \%$. The baseline values (time 0 ) for plasma electrolytes $\left(\mathrm{Na}^{+}-147.4 \pm 0.7 \mathrm{meq} / 1\right.$, $\left.\mathrm{K}^{+}-3.6 \pm 0.1 \mathrm{meq} / 1, \mathrm{Cl}^{-}-107.7 \pm 0.9 \mathrm{meq} / \mathrm{l}\right)$ and plasma osmolality $(291 \pm 2 \mathrm{mOsm} / \mathrm{l}) \mathrm{did}$ not show any consistent significant change during the experimental procedure.

A primarily respiratory acidosis (fig. 1B) occurred in all experimental animals. The values for $\mathrm{pH}$ and arterial $\mathrm{pCO}_{2}$ were significantly different at 15 min post-injection in 6 animals and at 30 min post-injection in 8 of the 9 animals. One hour after methadone injection, the $\mathrm{pH}$ had decreased to a mean of $7.253 \pm 0.012$ which was significantly different from the baseline value of $7.373 \pm 0.004$. Arterial $\mathrm{pCO}_{2}$ values were significantly elevated from a pre-injection mean value of $5.22 \pm 0.03$ $\mathrm{kPa}$ to $6.7 \pm 0.2 \mathrm{kPa}$ at $60 \mathrm{~min}$ post-injection. Arterial $\mathrm{pO}_{2}$ and bicarbonate levels did not show any consistent significant change. Base excess values decreased slightly but significantly from -1.5 \pm 0.1 to $-4.4 \pm 0.2 \mathrm{mmol} / 1$ prior to and following methadone administration respectively.

\subsection{Hemodynamic monitoring}

Mean arterial blood pressure calculated for the whole group showed no significant change from the baseline value of $117 \pm 2.8 \mathrm{~mm} \mathrm{Hg}$ during the experiment. The heart rate showed a significant and pronounced decrease in all animals. This occurred directly after methadone administration. Group averages for the heart rate were $101.5 \pm 2.8$ and $68.5 \pm 2.5$ beats per min before and after methadone administration, respectively.

\section{Discussion}

In order to study the relationship between opioid administration, plasma AVP levels and urine production in the dog, methadone was selected on account of its frequent use in canine 
anesthesia and because it is, like morphine, a true representative of the opiate agonist group.

Plasma AVP levels were all within the physiological range of $0-5 \mathrm{pg} / \mathrm{ml}$ (Cowley, 1982) before methadone administration. Since plasma AVP levels remained above the basal value during the entire post-injection period and in view of the fact that the plasma half-life of AVP is relatively short (Lauson, 1974), the continuous release of AVP over the $2 \mathrm{~h}$ test period should be considered. Furthermore various reports on metabolic clearance of AVP (Harvey et al., 1967; Matsui et al., 1983; Share et al., 1985) rule out the possibility of a decreased metabolic clearance rate with high plasma AVP levels.

Despite the absence of a time control group, we conclude that the rise in plasma AVP level cannot be attributed to a physiological variation during the time of the experiment. This statement is based on the magnitude of the increase as well as on the lack of increased plasma AVP during the first (control) hour of the experiment.

Thus, the question remains as to which factor is the principal stimulus for the supra-normal elevation of the plasma AVP levels. A recent report by Rockhold et al. (1983) has designated the morphine-induced fall in arterial blood pressure as the main factor elevating plasma AVP levels. This is contradicted by results from other experiments performed in rats (Aziz et al., 1981; Haldar, 1982; Grell et al., 1985) and rabbits (Firemark and Weitzman, 1979). No substantial fall in arterial blood pressure could be shown in the present experiments. Therefore, a cause and effect relationship between arterial blood pressure and plasma AVP levels is very unlikely in our experiments.

A factor which itself could cause a rise in plasma AVP level is the increased arterial $\mathrm{pCO}_{2}$. The AVP elevating properties of a hypercapnic and acidotic state have been well substantiated (Raff et al., 1983; Rose et al., 1984; 1985; Wang et al., 1984), although the 4.75-fold increase in AVP levels recorded in similar states of hypercapnic acidosis (Rose et al., 1985) is less than the rise we now saw. Considering the difference in magnitude of response and the difference in time course between plasma AVP levels (fig. 1A) and changes in blood gas and acid-base variables (fig. 1B) in this experiment we postulate that other factors besides the contribution of the respiratory acidosis must be jointly repsonsible for the elevated AVP levels.

It has been postulated in several reports that opioids play a regulatory role in the release of endogenous AVP (Aziz et al., 1981; Rockhold et al., 1983; Firemark and Weitzman, 1979; Van Wimersma Greidanus et al., 1979), although disagreement exists as to whether it is an inhibitory or stimulatory role. Van Wimersma Greidanus and Ten Haaf (1984) concluded in a recent review that the literature favors a suppressive influence of opiates and opioid peptides on vasopressin release although there is great species variability. It would seem that under the conditions of the present experiment the influence of methadone in the dog is a stimulatory one which further augments the response due to respiratory acidosis. The question whether this opiate influence takes effect through binding to specific opiate receptors remains to be elucidated by a study of the effect of naloxonemediated inhibition of opiate binding to opiate receptors.

AVP is considered to be one of the major determinants of urine production and urine osmolality. While the AVP levels in this experiment were $10 \mathrm{pg} / \mathrm{ml}$ or higher, a level considered sufficient for maximal antidiuresis, there was no significant decrease in urine production. The explanation for this phenomenon might be that the urine produced before methadone administration seemed maximally concentrated (1 440 \pm 87 mOsm/1). This implies that AVP, at least under these experimental circumstances, induces neither antidiuretic effect nor concentration of the urine produced. The fact that these experimental animals produced concentrated urine under basal conditions is a peculiarity which, in our opinion, was not due to the methodology but to the behavioral pattern of the dogs. Despite continuous access to drinking water, these animals drank only sufficient to maintain their fluid balance, with normal plasma AVP and osmolality levels as the result while they excreted a concentrated urine. The increase in urine production rate found during the experiment cannot be ascribed to changes in 
plasma AVP level or to hemodynamic changes. Since this phenomenon could be reproduced under similar circumstances during a different experiment (manuscript in preparation) it cannot be considered an accidental finding. Further investigations are in progress to clarify the underlying mechanisms.

Fieldman et al. (1985) ascribed an important role to the tonicity of the renal medulla and suggested that urine production and composition was influenced more by electrolyte load than by plasma AVP concentration. The lack of a change in urine solute concentration in our experiments could not substantiate this possibility. Furthermore, altered renal perfusion, or even distribution of perfusion within the kidney, could cause alterations in urine production and composition. Several studies (Liard et al., 1982; Moursi et al., 1985) have shown that total renal perfusion was unaltered after an AVP infusion which raised plasma AVP levels well above the physiological limits. Investigations on the distribution of intrarenal bloodflow however revealed bloodflow shifts from outer cortex to inner cortex and outer medulla (Akatsuka et al., 1977). The role of angiotensin II and the newer atrial peptides in regulating urine production and electrolyte excretion will also have to be studied more closely.

The experimental procedure included the handling of fully to semiconscious animals. Emotional stress is stated to cause a rise in the plasma AVP level (Rydin and Verney, 1939) and PCV (Berns et al., 1979). However, the stability of PCV in the pre-methadone time period excludes stress as a significant factor in increasing PCV or plasma AVP values. The rise in PCV after methadone administration could have been induced by the respiratory acidosis, as reported by Raff et al. (1983). The moderately severe respiratory acidosis can be ascribed to the sedative and respiratory depressive effect of methadone (Short et al., 1970). The decrease in base excess, which was within the physiological limits for dogs at all times (Pickrell et al., 1971), could have been caused by a reduction in peripheral perfusion due to a changed perfusion pattern following methadone administration (Heyndrickx et al., 1976; Liard et al., 1982).
In agreement with investigations which incorporated extensive circulatory monitoring, the relative bradycardia can be at least partially accounted for by the increased AVP level (Malayan et al., 1980; Montani et al., 1980; Liard et al., 1981; Undesser et al., 1985). These reports show that when plasma AVP levels are increased to an extent comparable with the levels reached in this experiment, there is an increase in total peripheral resistance without concurrent increase in mean arterial pressure. This is caused by a fall in cardiac output which is postulated to be centrally mediated through direct interaction of AVP with the central nervous system structures, possibly involving baroreceptor reflex pathways (Montani et al., 1980; Liard et al., 1981). Furthermore, the parasympathomimetic effect of methadone causes a decrease in heart rate (Hall and Clark, 1983).

The absence of changes in the high pressure system however does not exclude the possibility of changes in the low pressure system (Henry et al., 1967; Bie and Warberg, 1983). This is of special interest in view of the regulation of AVP under daily circumstances, which is thought to be mediated primarily through the low pressure system (Henry et al., 1967). Future studies in which circulatory variables, such as central venous pressure, left atrial or pulmonary artery wedge pressure, cardiac output and total peripheral resistance, are monitored may shed some light on this matter.

In conclusion, we report here a supra-physiological elevation of plasma AVP levels after the i.v. administration of methadone to conscious dogs. We propose that this elevation is independent of any major blood pressure change and only partially dependent on the concommitant rise of arterial $\mathrm{pCO}_{2}$. Plasma AVP does not exhibit an antidiuretic effect under these experimental circumstances, in which the animals receive no water load and are already producing maximally concentrated urine during the control period.

\section{Acknowledgements}

The authors wish to thank Ing. P. Gootjes, Mr. P. Van der Vlist and Mrs. A.E. Meijer for their technical assistance. Mrs. I. Clermont is thanked for secretarial work. 


\section{References}

Akatsuka, N., W.H. Moran, M.L. Morgan and M.F. Wilson, 1977, Effects of steady-state plasma vasopressin levels on the distribution of intrarenal blood flow on electrolyte excretion, J. Physiol. (London) 266, 567.

Aziz, L.A., M.L. Forsling and C.J. Woolf, 1981, The effect of intracerebroventricular injections of morphine on vasopressin release in the rat, J. Physiol. 311, 401.

Berns, A.S., R.J. Anderson and K.M. McDonals, 1979, Effect of hypercapnic acidosis on renal water excretion in the dog, Kidney Int. 15, 116

Bie, P. and J. Warberg, 1983, Effects on intravascular pressures of vasopressin and angiotensin II in dogs, Am. J. Physiol. 245, R906.

Cowley, A.W., 1982, Vasopressin and cardiovascular regulation, Int. Rev. of Physiol. 26, 189.

De Bodo, R.C., 1944, The antidiuretic action of morphine and its mechanism, J. Pharmacol. Exp. Ther. 82, 74.

Fieldman, N.R., M.L. Forsling and L.P. Le Quesne, 1985, The effect of vasopressin on solute and water excretion during and after surgical operations, Ann. Surg. 201, 383.

Firemark, H.M, and R.E. Weitzman, 1979, Effects of beta endorphin, morphine and naloxone on arginine vasopressin secretion and electroencephalogram, Neuroscience 4, 1895.

Galard, R., A. Sanmarti, R. Catalan, S. Schwartz and J.M. Castellanos, 1985, Study of different factors affecting arginine vasopressin radioimmunoassay, Clin. Chim. Acta $145,119$.

Glanzer, K., M. Appenheimer, F. Kruck, W. Vetter and H. Vetter, 1984, Measurement of $\mathrm{N}$-arginine vasopressin by radioimmunoassay, Acta Endocrinol. 106, 317.

Grell, S., J. Denker Christensen and B. Fjalland, 1985, Morphine antidiuresis in conscious rats: contribution of vasopressin and blood pressure, Acta Pharmacol. Toxicol. 56,38 .

Haldar, J., 1982, Release of antidiuretic hormone by morphine in rats: An in vivo and in vitro study, Proc. Soc. Exp. Biol. Med. 169, 113.

Hall, L.W. and K. Clark, 1983, Veterinary Anesthesia (Baillière \& Tindall, London) p. 64.

Harvey, N., J.J. Jones and J. Lee, 1967, The renal clearance and plasma binding of vasopressin in the dog, J. Endocrinol. $38,163$.

Henry, J.P., P.D. Gupta, J.P. Meehan, R. Sinclair and L. Share, 1967. The role of afferents from the low-pressure system in the release of antidiuretic hormone during non-hypotensive hemorrhage, Can. J. Physiol. Pharmacol. 46, 287.

Heyndrickx, G.R., D.H. Boettcher and S.F. Vatner, 1976, Effects of angiotensin, vasopressin, and methohexamine on cardiac function and blood flow distribution in conscious dogs, Am. J. Physiol. 231, 1579.

Huidobro-Toro, J.P., 1980, Antidiuretic effect of beta-endorphin and morphine in Brattleboro rats: development of tolerance and physical dependence after chronic morphine treatment, Br. J. Pharmacol. 71, 51.

Iwamoto, E.T. and W.R. Martin, 1981, Multiple opiate receptors, Med. Res. Rev. 1, 411.
La Rochelle, F.T., W.G. North and P. Stern, 1980, A new extraction technique of arginine vasopressin from blood: the use of octadecasilylsilica, Pflügers Arch. 387, 79.

Lauson, H.D., 1974, Metabolism of the neurohypophysial hormones, in: Handbook of Physiology, Vol. IV, section 7. Endocrinology, eds. E. Knobil and W.H. Sawyer (American Physiology Society, Washington DC, U.S.A.) p. 287.

Liard, J.F., O. Dériaz, P. Schelling and M. Thibonnier, 1982, Cardiac output distribution during vasopressin infusion or dehydration in conscious dogs, Am. J. Physiol. 243, H663.

Liard, J.F., O. Dériaz, M. Tschopp and J. Schoun, 1981, Cardiovascular effects of vasopressin infused into the vertebral circulation of conscious dogs, Clin. Sci. 61, 345.

Malayan, S.A., D.J. Ramsay, R.C. Keil and J.A. Reid, 1980, Effects of increases in plasma vasopressin concentration on plasma renin activity, blood pressure, heart rate, and plasma corticosteroid concentration in conscious dogs, Endocrinology $107,1899$.

Matsui, K., L. Share, B.C. Wang, J.T. Crofton and D.P. Brooks, 1983, Effects of changes in steady state plasma vasopressin levels on renal and urinary vasopressin clearances in the dog, Endocrinology 112, 2107.

Montani, J.P., J.F. Liard, J. Schoun and J. Möhring, 1980, Hemodynamic effects of exogenous and endogenous vasopressin at low plasma concentrations in conscious dogs, Circ. Res. 47, 346.

Montastruc, J.L., F. Morales-Olivas and P. Montastruc, 1980, Effect of morphine on diuresis in normal and diabetes insipidus dogs, Arch. Farmacol. Toxicol. 6, 287

Moursi, M.M., D.G.L. Van Wylen and L.G. D'Alecy, 1985, Regional blood flow changes in response to midly pressor doses of triglycyl desamino lysine and arginine vasopressin in the conscious dog, J. Pharmacol. Exp. Ther. 232, 360.

Pickrell, J.A., S.E. Dubin and J.C. Elliot, 1971, Normal respiratory parameters of unanesthetized beagle dogs, Lab. Anim. Sci. 21, 677.

Raff, H., J. Shinsako, L.C. Keil and M.F. Dallman, 1983, Vasopressin, ACTH and corticosteroids during hypercapnia and graded hypoxia, Am. J. Physiol. 244, E453.

Rockhold, R.W., J.T. Crofton, B.C. Wang and L. Share, 1983, Effect of intracarotid administration of morphine and naloxone on plasma vasopressin levels and blood pressure in the dog, J. Pharmacol. Exp. Ther. 224, 336.

Rodbard, D. and J.E. Lawald, 1970, Computer analysis of radioligand assay and radioimmunoassay data, Acta Endocrinol. 79 (Suppl.), 147.

Rose, C.E., R.J. Anderson and R.M. Carey, 1985, Acute hypercapnic acidosis diminishes renal water excretion in conscious dogs, Miner. Electrolyte Metab. 11, 131.

Rose, C.E., R.L. Godine, K.Y. Rose, R.J. Anderson and R.M. Carey, 1984, Role of arginine vasopressin and angiotensin II in cardiovascular responses to combined acute hypoxemia and hypercapnic acidosis in conscious dogs, J. Clin. Invest. 74, 321.

Rydin, H. and E.B. Verney, 1939, The inhibition of water-diuresis by emotional stress and by muscular exercise, Q.J. Exp. Physiol. 27, 343. 
Share, L., T. Kimura, K. Matsui, R.E. Shade and J.T. Crofton. 1985, Metabolism of vasopressin, Fed. Proc. 44, 59.

Short, C.E., W. Greenwald and F. Bendick, 1970, Oxygen, carbon dioxide, and $\mathrm{pH}$ responses in arterial blood of dogs given analgesic, neuroleptanalgesic and ataractic agents, J. Am. Vet. Med. Ass. 156, 1406.

Undesser, K.P., E.M. Hasser, J.R. Haywood, A.K. Johnson and V.S. Bishop, 1985, Interactions of vasopressin with the area postrema in arterial baroreflex function in conscious rabbits, Circ. Res. 56, 410.

Van Wimersma Greidanus, Tj.B. and J.A. Ten Haaf, 1984,
Opioids and the posterior pituitary, in: Delitala, Opioid Modulation of Endocrine Function (Raven Press, Ncw York) p. 125.

Van Wimersma Greidanus, Tj.B., T.J. Thody, H. Verspaget, G.A. De Rotte, H.J.H. Goedemans, G. Croiset and J.M. $V$ an Ree, 1979, Effects of morphine and beta-endorphin on basal and elevated levels of alpha-MSH and vasopressin, Life Sci. 24, 579.

Wang, B.C., W.D. Sundet and K.L. Goetz, 1984, Vasopressin in plasma and cerebrospinal fluid of dogs during hypoxia or acidosis, Am. J. Physiol. 247. E449. 